Thorax, 1979, 34, 789-793

\title{
Small cell carcinoma: combined approach to treatment
}

\author{
ANNA GREGOR, P G M MORGAN, R L MORGAN, F H SCADDING, \\ AND M TURNER-WARWICK \\ From the Department of Medicine, Brompton Hospital, and the Department of Radiotherapy \\ and Oncology, Royal Marsden Hospital, London, UK
}

ABSTRACT Fifty-six patients with untreated small cell carcinoma of the bronchus were treated with three courses of chemotherapy (cyclophosphamide, vincristine, and procarbazine and methotrexate) and assessed for response. Thirty-one patients $(55.4 \%)$ were classified as responders; they were given a course of radiotherapy and were then randomly allocated to continued cyclical chemotherapy or no further chemotherapy until relapse. Non-responders to chemotherapy were treated with radiotherapy or palliatively. The median survival was 10.5 months in responders and 6 months in non-responders $(P<0.01)$. The one-year survival in responders was $42 \%$. There was no statistical difference in survival between patients treated with continued chemotherapy and those treated at relapse. Sixty-nine per cent of patients experienced no side effects from chemotherapy.

Three indicators of non-response to chemotherapy were identified - exercise tolerance at diagnosis, macroscopic liver metastases, and inappropriate $\mathrm{ADH}$ secretion.

Small cell carcinoma of the bronchus is a disseminated disease in most patients at presentation (Selawry, 1974). After reports of response and improved survival using radiotherapy (Miller et al, 1969), and chemotherapy (Selawry et al, 1974) we have tested whether a combination of chemotherapy and radiotherapy could be used to prolong useful life and whether prognostic factors could be identified.

\section{Methods}

Previously untreated patients with histologically confirmed small cell bronchial carcinoma and adequate renal function were included. From October 1975 to October 197756 patients (42 male, 14 female) were treated. Their ages ranged from 44 to 74 (mean 61.2). The diagnosis was obtained in 48 cases $(85.7 \%$ ) by fibreoptic bronchoscopy, in five $(8.9 \%)$ by rigid bronchoscopy, in two $(3.6 \%)$ at operation, and in one $(1 \cdot 8 \%)$ by sputum cytology. At entry into the trial patients' exercise tolerance was assessed, and histology was reviewed by a consultant histopathologist. The proposed treatment, including possible side effects, was discussed with the patient before giving treatment. Investi- gations after history and full clinical examination included:

(1) Chest radiograph, PA and lateral: mediastinal tomography.

(2) Erythrocyte sedimentation rate and full blood count.

(3) Urea and electrolytes, serum calcium, phosphate, and creatinine estimations.

(4) Standard liver function tests (alkaline phosphatase, gamma glutamyltranspeptidase, aspartate transaminase, lactic dehydrogenase, creatinine phosphokinase, and bilirubin).

(5) Cortisol levels (morning and midnight), paired plasma and urinary osmolalities.

(6) Liver and bone scintiscans, using ${ }^{99 \mathrm{~m}}$ technecium sulphur colloid.

(7) Bone marrow aspiration and trephine biopsy.

The patients' exercise tolerance was assessed on a scale of $0-4(0=$ normal, $1=$ breathless after two flights of stairs, $2=$ breathless after one flight of stairs, $3=$ breathless on the flat, $4=$ breathless at rest), and level of activity on a modification of the Karnofsky scale (Karnofsky, $1956 \quad(0=$ normal, $1=$ ambulant, 2 =housebound, $3=$ bedbound). Information was recorded on proforma sheets for each patient. 
Cyclical chemotherapy consisted of courses of cyclophosphamide, $1 \mathrm{~g}$, and vincristine, $1 \mathrm{mg}$, both intravenously, methotrexate $200 \mathrm{mg}$ (as a 24-hour infusion), and procarbazine $500 \mathrm{mg}$ in two daily doses. Folinic acid was given at the end of the methotrexate infusion. The patients were given antiemetics. All patients received three courses of chemotherapy at three-weekly intervals and were then assessed for response, objectively and subjectively. Toxicity was carefully recorded. Chest radiographs, full blood count, and full biochemical profile were repeated before each course. Levels of $3.0 \times 10^{9} / 1$ white cells and $100 \times 10^{9} / 1$ platelets were taken as adequate for chemotherapy. Radioisotope scans were repeated when indicated.

Patients remained under the care of the referring physician but their management was supervised by the oncologist co-ordinating the study (AG).

Criteria of response were at least a $50 \%$ reduction in measurable tumour diameter in two planes, as judged by two observers, with no evidence of differential progression and no evidence of emergence of previously undetected metastases. Responders and non-responders with intrathoracic disease only then received irradiation to the primary tumour, mediastinum, and supraclavicular fossae. A tumour dose of 3500 rads was delivered over four weeks (five times a week fractionation), through two parallel opposed treatment portals using megavoltage apparatus.

Responders were randomly allocated to a group whose chemotherapy continued for six months from diagnosis or until relapse (17 patients, 54.8\%) or a group who had no further chemotherapy after irradiation until relapse (14 patients, $45 \cdot 2 \%$ ). Nonresponders with extensive disease were treated palliatively, including irradiation as indicated.

Patients receiving regular chemotherapy were admitted for two days every three weeks; patients not receiving regular cycles of chemotherapy were assessed on an outpatient basis. Patients included in the trial were followed up until January 1978.

\section{Results}

At entry into the trial $33(58.9 \%)$ patients had only intrathoracic disease detected (Eagan et al, 1973) while $23(41 \cdot 1 \%)$ had evidence of extrathoracic involvement. Liver metastases shown by a positive liver scan were seen in eight (14.3\%) patients, four $(7.1 \%)$ had positive bone scans, five $(8.9 \%)$ had positive bone marrow aspiration, one $(1.8 \%)$ had skin deposits, and six $(10.7 \%)$ had evidence of inappropriate antidiuretic hormone secretion as shown by hyponatraemia $(\mathrm{Na}+<125$ 응 $\mathrm{mmol} / \mathrm{l}$ ) in the presence of urinary to plasma $\frac{\bar{c}}{\mathrm{~s}}$ osmolality ratio of $3: 1$ or greater. No patients $\overrightarrow{\mathbb{D}}_{\overparen{D}}$ had detectable inappropriate corticotrophin secretion, and no patients presented with intracranialis tumour at the time of diagnosis.

Thirty-one patients showed objective response $-\overrightarrow{-}$ to chemotherapy, giving an overall objective re- $\vec{\sigma}$ sponse rate of $55 \cdot 4 \%$. Patients' sex had no influence on response to chemotherapy with $22(71 \%)$ men and nine $(29 \%)$ women among responders, $\stackrel{\omega}{+}$ and $20(80 \%)$ men and five $(20 \%)$ women among. non-responders. Ages ranged from 44 to 73 (meanoo 60 ) among responders and 40 to 74 (mean $62 \cdot 2$ ) for 0 non-responders. The extent of disease and sites affected at the time of diagnosis and their relation $\vec{\square}$ to response to chemotherapy are summarised in ${ }_{\odot}^{\mathbb{D}}$ table 1 . The patient's exercise tolerance at the $\frac{\mathbb{\Phi}}{3}$ time of diagnosis and its influence between re-sponders and non-responders who performed nor- mally is significant; the difference becomes pro- $\vec{\theta}$ gressively less with increased grade of disability. ढै

Table 1 Extent of disease at diagnosis

\begin{tabular}{|c|c|c|c|c|c|c|c|}
\hline & \multicolumn{2}{|c|}{ Total } & \multicolumn{2}{|c|}{ Responders } & \multicolumn{2}{|c|}{$\begin{array}{l}\text { Non- } \\
\text { responders }\end{array}$} & \multirow[t]{2}{*}{$\mathbf{P}$} \\
\hline & No & $\%$ & No & $\%$ & No & $\%$ & \\
\hline Limited & 33 & $58 \cdot 9$ & 21 & $67 \cdot 7$ & 12 & $48 \cdot 0$ & NS \\
\hline Extensive & 23 & $41 \cdot 9$ & 10 & $32 \cdot 3$ & 13 & $52 \cdot 0$ & \\
\hline Liver & 8 & $14 \cdot 3$ & 2 & $6 \cdot 5$ & 6 & $24 \cdot 0$ & $<0.05$ \\
\hline Bone & 4 & $7 \cdot 1$ & 2 & $6 \cdot 5$ & 2 & 80 & \\
\hline Bone marrow & 6 & $10 \cdot 7$ & 3 & $9 \cdot 7$ & 3 & $12 \cdot 0$ & NS \\
\hline Paraneoplastic & 6 & $10 \cdot 7$ & 1 & $3 \cdot 2$ & 5 & $20 \cdot 0$ & $<0.05$ \\
\hline
\end{tabular}

Table 2 Exercise performance at diagnosis

\begin{tabular}{|c|c|c|c|c|c|c|c|}
\hline \multirow[t]{2}{*}{ Performance } & \multicolumn{2}{|c|}{ Total } & \multicolumn{2}{|c|}{ Responders } & \multicolumn{2}{|c|}{$\begin{array}{l}\text { Non- } \\
\text { responders }\end{array}$} & \multirow[t]{2}{*}{$\mathbf{P}$} \\
\hline & $N o$ & $\%$ & No & $\%$ & No & $\%$ & \\
\hline Normal & 37 & $66 \cdot 1$ & 25 & 806 & 12 & $48 \cdot 0$ & $<0.01$ \\
\hline Ambulant & 6 & $10 \cdot 7$ & 2 & $6 \cdot 5$ & 4 & $16 \cdot 0$ & $<0.05$ \\
\hline House bound & 10 & 179 & 2 & 65 & 8 & 320 & NS \\
\hline Bed bound & 3 & 54 & 2 & 65 & 1 & 40 & NS \\
\hline
\end{tabular}

The survival rates as an actuarial survival, calculated by the life table method, of the totale group, responders and non-responders, are shown (fig 1). Median survival of the whole group waso eight months compared to six months in non- $\bar{D}$ responders treated with radiotherapy and $10.5 \%^{\text {? }}$ months in the group of 31 responders. One-year survival was $42 \%$ for responders as compared to $4 \%$ for non-responders $(P<0.05)$. Of the 31 re- ${ }_{P}$ sponders, 21 died during the time of our follow-up, $\stackrel{\mathbb{Q}}{\varrho}$ six have survived for less, and four for more, thane one year. Of the non-responders, only two are 


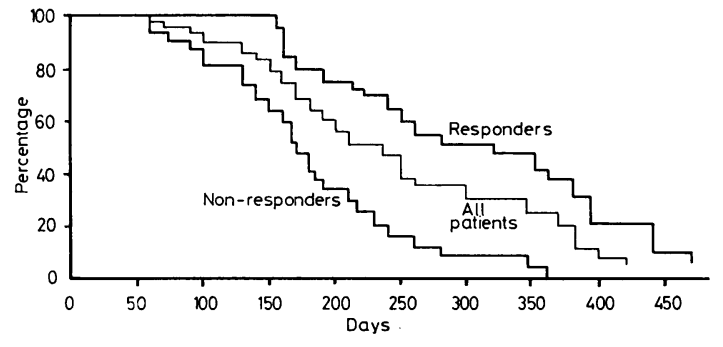

Fig 1 Survival by actuarial analysis.

alive at 60 and 170 days respectively. The mean \pm SE and median survivals of subgroups of responders and non-responders are summarised (fig 2). There was a significant difference in survival between responders and non-responders with localised disease $(\mathrm{P}<0.05)$ and with extrathoracic disease $(\mathrm{P}<0.01)$. No statistical difference was observed in survival rates of responders who continued chemotherapy compared to those treated only on relapse. Of the 31 patients who responded, 18 patients $(58.19 \%)$ relapsed, $50 \%$ of these at two or more sites (table 3). Seven patients relapsed in the site of original disease, two in the liver, and five in the lung. The favoured site for metastases was the brain (seven) and liver (six). The mean time interval between the development of metastases and the end of treatment was 95 days for brain and 102 days for liver. Of the 13 responders who did not relapse, 11 are alive at the time of writing and two died from conditions unrelated to their bronchial carcinoma. Once relapse occurred, prognosis was poor despite further treatment. Sixteen patients $(89 \%)$ died within 70 days of relapse; two patients survived 180 days and 251 days.

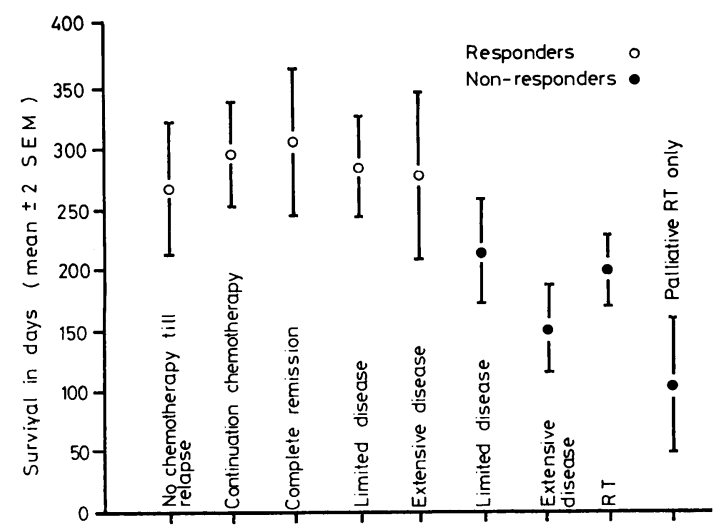

Fig 2 Survivals of subgroups of responders and non-responders.
Table 3 Relapses

\begin{tabular}{|c|c|c|c|c|c|}
\hline $\begin{array}{l}\text { Major site } \\
\text { of disease }\end{array}$ & Relapse site & No & $\begin{array}{l}\% \\
\text { Patients }\end{array}$ & $\begin{array}{l}\text { Mean time } \\
\text { end of } \\
\text { treatment } \\
\text { to relapse } \\
\text { (days) }\end{array}$ & $\begin{array}{l}\text { Mean time } \\
\text { relapse to } \\
\text { death } \\
\text { (days) }\end{array}$ \\
\hline Responders & $\begin{array}{l}\text { Lung } \\
\text { Non- } \\
\text { irradiated site } \\
\text { Irradiated site } \\
\text { Brain } \\
\text { Liver } \\
\text { Bone } \\
\text { Skin } \\
\text { Lymph node } \\
\text { None }\end{array}$ & $\begin{array}{c}7 \\
(2) \\
\\
(5) \\
7 \\
6 \\
4 \\
1 \\
1 \\
13\end{array}$ & $\begin{array}{c}22 \cdot 6 \\
(6 \cdot 4) \\
\\
(16 \cdot 1) \\
22 \cdot 6 \\
19 \cdot 3 \\
10 \cdot 9 \\
3 \cdot 2 \\
3 \cdot 2 \\
41 \cdot 9\end{array}$ & $\begin{array}{l}\text { On } \\
\text { treatment } \\
47 \\
95 \\
102 \\
128 \\
4 \\
98 \\
-\end{array}$ & $\begin{array}{l}72 \\
76 \\
26 \\
25 \\
17 \\
70 \\
18 \\
-\end{array}$ \\
\hline $\begin{array}{l}\text { Non- } \\
\text { responders }\end{array}$ & $\begin{array}{l}\text { Brain } \\
\text { Liver } \\
\text { Bone } \\
\text { Skin } \\
\text { Lymph node } \\
\text { None }\end{array}$ & $\begin{array}{l}4 \\
8 \\
3 \\
1 \\
4 \\
3\end{array}$ & $\begin{array}{r}16 \\
32 \\
12 \\
4 \\
16 \\
12\end{array}$ & & \\
\hline
\end{tabular}

The side effects of chemotherapy are summarised in table 4 . The early side effects are those observed during the initial trial of chemotherapy; $69 \%$ had no side effects while $12.5 \%$ had nausea and vomiting, the commonest side effect. On longterm chemotherapy the most troublesome side effects were nausea and vomiting that in three patients necessitated discontinuation of treatment. Two patients developed depression and refused further chemotherapy. One patient developed paraesthesiae after a total dose of $6 \mathrm{mg}$ vincristine.

Table 4 Side effects during the study

\begin{tabular}{|c|c|c|c|c|c|c|}
\hline \multirow[t]{2}{*}{ Nature } & \multicolumn{2}{|c|}{ Total } & \multicolumn{2}{|c|}{ Responders } & \multicolumn{2}{|c|}{$\begin{array}{l}\text { Non- } \\
\text { responders }\end{array}$} \\
\hline & No & $(\%)$ & No & $(\%)$ & No & $(\%)$ \\
\hline \multicolumn{7}{|l|}{ Early } \\
\hline $\begin{array}{l}\text { Nausea, vomiting, } \\
\text { weight loss }\end{array}$ & 7 & $(12 \cdot 5)$ & 3 & $(9 \cdot 7)$ & 4 & $(16 \cdot 0)$ \\
\hline Depression, malaise & 3 & $(5 \cdot 4)$ & 2 & $(6 \cdot 5)$ & 1 & $(4 \cdot 0)$ \\
\hline Chemical conjunctivitis & 5 & $(8 \cdot 9)$ & 4 & $(12 \cdot 9)$ & 1 & $(4 \cdot 0)$ \\
\hline Marrow toxicity & 1 & $(1 \cdot 8)$ & 0 & $(0 \cdot 0)$ & 1 & $(4 \cdot 0)$ \\
\hline None & 39 & $(69 \cdot 6)$ & 21 & $(67 \cdot 7)$ & 18 & $(72 \cdot 0)$ \\
\hline \multicolumn{7}{|l|}{ Late } \\
\hline $\begin{array}{l}\text { Nausea, vomiting, } \\
\text { weight loss }\end{array}$ & 7 & $(22 \cdot 6)$ & 7 & $(22 \cdot 6)$ & & \\
\hline Depression, malaise & - & $(0 \cdot 0)$ & - & $(0 \cdot 0)$ & & \\
\hline Chemical conjunctivitis & 2 & $(6 \cdot 5)$ & 2 & $(6 \cdot 5)$ & & \\
\hline Marrow toxicity & 5 & $(16 \cdot 1)$ & 5 & $(16 \cdot 1)$ & & \\
\hline Infections & 1 & $(3 \cdot 2)$ & 1 & $(3 \cdot 2)$ & & \\
\hline Neurotoxicity & 1 & $(3 \cdot 2)$ & 1 & $(3 \cdot 2)$ & & \\
\hline None & 11 & $(35 \cdot 5)$ & 11 & $(35 \cdot 5)$ & & \\
\hline
\end{tabular}

Of the patients who were on long-term chemotherapy, $47 \%$ had no complications. Partial alopecia was well accepted, and wigs were provided routinely. 


\section{Discussion}

We have confirmed that responders to chemotherapy in terms of reduction in tumour size also survive significantly longer than non-responders (Eagan et al, 1973). COMP was used as our chemotherapy combination for the following reasons. Cyclophosphamide and methotrexate have reported activity when used singly (Selawry et al, 1974). Procarbazine has not been adequately tested on bronchial carcinoma (Selawry, 1974), and vincristine has been chosen for its reported synchronising action in combinations (DeVita and Schein, 1973). The drugs were given over 24 hours every three weeks to minimise haematological toxicity (Hill and Baserga, 1975). While addition of 1-chloroethyl-3-cyclohexyl-1-nitrosurea (CCNU) or adriamycin might have given a higher response rate (Livingstone et al, 1976), the much higher toxicity associated with their administration was in our view not acceptable for this type of study.

We chose to give three courses of chemotherapy initially to allow us to assess individual response early, as we felt that even relatively non-toxic chemotherapy should not be given when it has no demonstrable activity. Moreover, reduction of tumour mass may make subsequent radiotherapy more effective (Fletcher and Shukovsky, 1975). From a previous study the postponement of radiotherapy had no deleterious effect on survival (Gilby et al, 1977).

Two prognostic indicators of future non-response to chemotherapy were the presence of hepatic involvement and inappropriate ADH secretion. Of the eight patients who had positive liver scan at diagnosis, six $(75 \%)$ were among the nonresponders $(P<0.05)$. Five out of six patients with demonstrably inappropriate ADH secretion failed to respond to chemotherapy $(\mathrm{P}<0.05)$. Bone marrow involvement at diagnosis carried no adverse prognostic significance and was not associated with increased haematological toxicity.

The correlation of exercise tolerance at diagnosis with survival is well known (Johnson et al, 1976). Its influence on objective response to chemotherapy is a new finding needing explanation. Of the responders, $80 \%$ were leading a normal life at the time of presentation as compared to $48 \%$ of non-responders $(P<0.01)$. This cannot be explained by better tolerance of chemotherapy, as all patients received three courses and major toxicity was minimal and comparable in both groups. Patients' clinical state may reflect the true extent of the disease more accurately than available methods of detection.
Response to chemotherapy may be a marker $\frac{\mathrm{O}}{\mathrm{C}}$ selecting a group with better prognosis. This may $\frac{\bar{\sigma}}{\bar{\omega}}$. be due to biological and behavioural differences of $\frac{\mathbb{D}}{\mathbb{D}}$ the tumours, so far unidentified in descriptive $\varrho$ classifications based on tissue morphology. Support o comes from the low response rate and poor sur- $\overrightarrow{0}$ vival in patients with demonstrably inappropriate $\overrightarrow{\vec{H}}$ ADH secretion. When designing new trials, these $\vec{\sigma}$ factors, unless taken into account, may influence $\overrightarrow{\overrightarrow{2}}$ the outcome of the study and invalidate results $\vec{x}$ obtained.

The median survival of the whole group, eight months, compares favourably with other studies of using radiotherapy and chemotherapy alone $\circ$ (Eagan et al, 1973; Hansen et al, 1971). The ability to assess individual response to chemotherapy 0 made differential evaluation of survival results $\varnothing$ possible and confirms previous suspicions that $\stackrel{\mathbb{N}}{3}$ benefit can be obtained only in patients showing $\underset{\mathbb{\Phi}}{\overparen{D}}$ definite response in measurable tumour mass. The median survival of responders was 10.5 months as compared to 5.8 months in non-responders treated 6 with radiotherapy alone. This is also reflected in the one-year survival of $42 \%$ in responders, $4 \%$ in non-responders, and $36 \%$ in the group as a whole $(\mathrm{P}<0.05)$. We do not know whether effective chemotherapy prolongs survival or simply selects $\stackrel{\mathbb{Q}}{\unrhd}$ a group of patients with favourable prognosis, but $\vec{F}$ the ability to identify prognostic factors justified, $\frac{3}{3}$ in our view, this type of study. Responders randomly allocated to continuation of chemotherapy survived longer than the group in which chemotherapy was withheld until relapse, although the 으 difference did not reach statistical significance. Once relapse occurred, remission was not obtained despite the prompt administration of drugs to which the tumour had been sensitive at presenta- $\frac{\delta}{8}$ tion. This is reflected in the shorter median survival ( 8.1 months) and in the short interval between 의 relapse and death. We would recommend that $\supset$ once response to a particular chemotherapy combination is established in an individual patient, $N$ prolonged maintenance should be given, despite there being no clinical evidence of disease. The $\stackrel{N}{0}$ optimal length of treatment for this tumour is $\mathrm{w}$ not known and will be the subject of a further $\bar{Q}$ study.

At the time of writing $58 \%$ of the responders had relapsed, but only two $(6.4 \%)$ were receiving chemotherapy at the time of relapse. In both patients tumour recurred in the non-irradiated $\stackrel{\circ}{\mathbb{D}}$ lung (CR) suggesting that in the presence of $\frac{?}{\Phi}$ response to chemotherapy, local irradiation may $\cong$ increase effective control. Five $(16 \cdot 1 \%)$ tumours recurred in previously irradiated lung, all in 8 
patients off chemotherapy at the time. Chemotherapy can help to control residual disease not sterilised by radiotherapy. Extent of disease at diagnosis and complete remission after three courses of chemotherapy did not influence survival in responders.

Non-responders with limited disease survived longer than those with extrathoracic involvement $(P<0.05)$. This is due to the small survival gain achieved by radiotherapy in patients with thoracic disease only (Miller et al, 1969). (The median survival of 2.8 months in the four non-responders who received palliative treatment only would not have been improved by radiotherapy as they all had massive extrathoracic disease.)

Small cell carcinoma has a well-documented propensity (Johnson et al, 1976) to metastasise to the brain, and $22.6 \%$ of responders developed metastases in this protected site. Despite this, we would not advocate prophylactic whole brain irradiation routinely as resulting toxicity may jeopardise chemotherapy and irradiation necessary for control of the systemic disease (Johnson et al, 1976). In patients with good and prolonged response, however, its use may further increase disease-free survival by reducing the incidence of relapse at this site. This will be examined in a further study.

Complications of chemotherapy were rare; the first three courses, which tested tumour sensitivity, were tolerated without any complications in $70 \%$ of cases, irrespective of their tumour response. In the patients with side effects, nausea, vomiting, and anorexia were commonest $(12 \cdot 5 \%)$. This was slightly more common in non-responders $(16 \%)$ than responders $(9.7 \%)$. Chemical conjunctivitis associated with high dose methotrexate infusion occurred in $9 \%$ of cases. This was never severe and subsided spontaneously over 24 hours when folinic acid was given. Marrow toxicity as judged by failure of the peripheral blood count to return to levels of $3.0 \times 10^{9}$ leucocytes and $100 \times 10^{9}$ platelets three weeks after a preceeding course occurred in one patient only in this trial period and in five patients receiving maintenance chemotherapy $(16 \%)$. In no case was this life-threatening, and in only one case was the resulting neutropenia associated with respiratory infection. In the responder group receiving maintenance chemotherapy, the incidence of nausea and vomiting was $22.6 \%$. Vincristine neurotoxicity with paraesthesiae occurred in one patient only, after a total dose of $6 \mathrm{mg}$. Possibly in this older population the small dose $(1 \mathrm{mg})$ of vincristine chosen accounted for this low incidence.
We thank consultants who referred patients for this study, Dr Juliette Hillman for invaluable help at the onset of the trial, Dr Brian Heard for histological studies, and the nursing staff.

\section{References}

DeVita, V T, and Schein, P S (1973). The use of drugs in combination for the treatment of cancer: rationale and results. New England Journal of Medicine, 288, 998-1006.

Eagan, R T, Maurer, L H, Forcier, R J, and Tulloh, $M$ (1973). Combination chemotherapy and radiation therapy in small cell carcinoma of the lung. Cancer, 32, 371-379.

Fletcher, G H, and Shukovsky, L J (1975). The interplay of radiocurability and tolerance in the irradiation of human cancers. Journal de Radiologie d'Electrologie et de Medicine Nucleare, 56, 383-400.

Gilby, E D, Bondy, P K, Morgan, R L, and McElwain, $T$ J (1977). Combination chemotherapy for small cell carcinoma of the lung. Cancer, 39, 1959-1966.

Hansen, H H, Muggia, F M, and Selawry, O S (1971). Bone marrow examination in 100 consecutive paticnts with bronchogenic carcinoma. Lancet, 2, 443-445.

Hill, B T, and Baserga, R (1975). The cell cycle and its significance for cancer treatment. Cancer Treatment Reviews, 2, 159-175.

Johnson, R E, Brereton, H D, and Kent, H C (1976). Small-cell carcinoma of the lung: attempt to remedy causes of past therapeutic failure. Lancet, 2, 289-291.

Karnofsky, D A (1956). Chemotherapy of lung cancer. In Pulmonary Carcinoma, edited by E Mayer and H C Maier, pp 384-397. Lippincott, Philadelphia.

Livingstone, R B, Fee, W H, Einhorn, L H, Burgess, M A, Freireich, E J, Gottlieb, J A, Farber, M O (1976). BACON (bleomycin, adriamycin, CCNU, oncovin and nitrogen mustard) in squamous lung cancer. Cancer, 37, 1237-1242.

Miller, A B, Fox, W, and Tall, R (1969). Five year follow-up of the Medical Research Council comparative trial of surgery and radiotherapy for the primary treatment of small-celler or oat-celled carcinoma of the bronchus. Lancet, 2, 501-505.

Selawry, O S (1974). The role of chemotherapy in the treatment of lung cancer. Seminars in Oncology, 1, 217-228.

Selawry, O S, Hansen, H H, Carr, D, Sealy, R, and Sunan, R (1974). Improved chemotherapy for advanced bronchogenic carcinoma. Proceedings of the American Association for Cancer Research, 15, 118.

Requests for reprints to: Professor $M$ TurnerWarwick, Department of Medicine, Brompton Hospital, Fulham Road, London SE3 6HP. 